\section{Original Article}

\author{
Dr. Mahmood Sajedeen \\ BDS, FCPS \\ Assistant Professor \\ Dept. of Orthodontics \\ Bangabandhu Sheikh Mujib \\ Medical University \\ Dr. Gazi Shamim Hassan \\ BDS, PhD, FWFO \\ Chairman \& Associate Professor \\ Dept. of Orthodontics \\ Bangabandhu Sheikh Mujib \\ Medical University \\ Dr. Ashis Kumar Biswas \\ BDS, MCPS, FCPS \\ Orthodontics and \\ Dentofacial Orthopedics
}

\title{
Comparison on Intermolar width among Different types of Malocclusion of Bangladeshi Population
}

\section{Abstract : \\ Objectives :}

To compare inter-molar width of different classes of dento-alveolar malocclusion in the permanent dentition.

\section{Materials and Methods :}

This study was done at Department of Orthodontics, BSMMU between 1st July 2007 to 1st January 2011.96 study patient was selected . inter-molar width were measured from dental casts of this Bangladeshi subjects of which 48 male, 48 female, 24 class 1, 24 class 2 div. I, 24 class 2 div. II, 24 class III. A slide calipers with a vernier scale was used to measure the inter-molar width and compared among different malocclusion classes.

\section{Results :}

Intermolar width in maxilla was found maximum in class I malocclusion but Intermolar width in mandible was maximum in class III malocclusion . Least significant difference (LSD) is used to compare two of the four group . $\mathrm{P}<0.05$ was set as the level of significance.

\section{Conclusions :}

Statistically significant difference $(\mathrm{p}=0.0018)$ was found when the results is compared among the four malocclusion groups (Table 4). No group showed any significant difference except Class I and Class III, Class II div.1 and Class III, Class II div. 2 and Class III, when compared individually using LSD test (Table 3).

\section{Introduction :}

Dental arch forms have considerable implications in orthodontic diagnosis and treatment planning, as it affects the space available, dental aesthetics, and stability of the dentition. These considerations, in association with the antero-posterior movements of the dentition, will determine the requirements for extraction or non extraction treatment [1]. Arch width have been used to provide estimations of arch form. [2]. Arch width is measure by estimation intermolar width [3].

Very few information are available about dental arch dimen- sions of permanent dentition in Bangladeshi population.

In a study in our country, ideal arch form, arch width and arch length in normal occlusion group of 100 (50 males and 50 females) Bangladeshi subjects and auther found that in maxilla intermolar width is $49.18 \mathrm{~mm}$ in male and $47.58 \mathrm{~mm}$ in female [4] The literature review indicates that many investigators found differences intermolar width in different types of malocclusion, as a result, a comparative study was required to standardized the arch dimension of permanent dentition of Bangladeshi population . 


\section{Specific Objectives:}

To compare the intermolar width on the dental cast among dento-alveolar Class I, Class II and Class III malocclusion groups.

\section{Materials and Methods :}

This study was done at the Department of Orthodontics, Faculty of Dentistry, Bangabandhu Sheikh Mujib Medical University from 1st July 2007 to 1st January 2011 with a sample size of 96 patients. At first study model was prepared with stone plaster pouring it into impression of maxillary and mandibular arch. Patients detail is collected from departmental record bookThen data of this study is measured with slide calipers and $0.5 \mathrm{~mm}$ brass wire and recorded in the data collection sheet.

\section{Data collection procedure:}
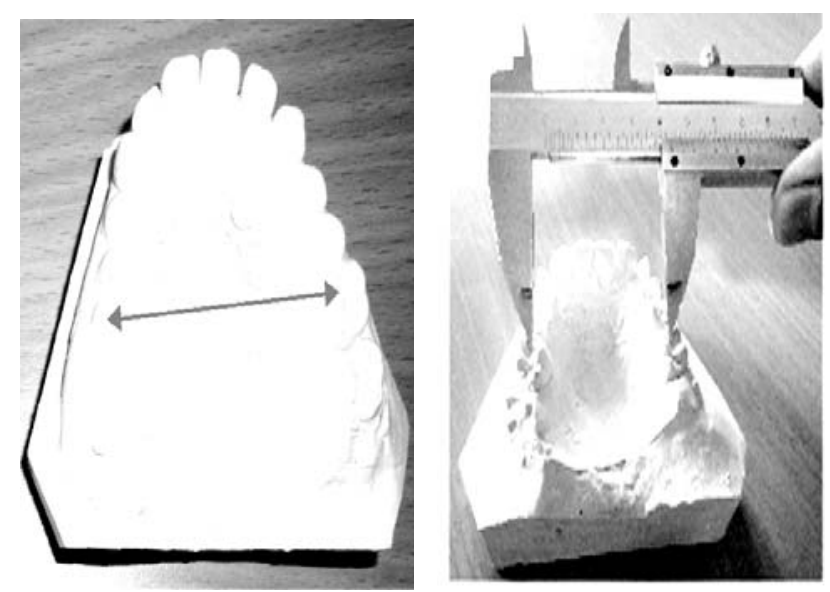

Figure 1: Measurement of intermolar width

Molar arch width- horizontal distance between the central fossae of right and left first permanent molars [4]

\section{Data analysis:}

The variable of this study are Mandibular inter-molar width (man IMW), maxillary inter-molar width (maxi IMW). Data of this study are computerized and analyzed using SPSS for window version 10, strata version 10. One -way analysis of the variables (ANOVA) is used to check the statistical significance of the variables among Class I, Class II division 1, Class II division 2, Class III malocclusions. Least significant difference (LSD) is used to compare two of the four group . $\mathrm{P}<0.05$ is set as the level of significance.

\section{Results :}

\begin{tabular}{|c|c|c|c|}
\hline \multicolumn{4}{|c|}{$\begin{array}{c}\text { Table 1: Distribution of subjects according to } \\
\text { gender and malocclusion groups }\end{array}$} \\
\hline $\begin{array}{c}\text { Malocclusion } \\
\text { group }\end{array}$ & $\begin{array}{c}\text { Number } \\
\text { of males }\end{array}$ & $\begin{array}{c}\text { Number } \\
\text { of } \\
\text { females }\end{array}$ & Total \\
\hline Class-I & 12 & 12 & 24 \\
Class-II & 12 & 12 & 24 \\
division 1 & 12 & 12 & 24 \\
Class-II & 12 & & \\
division 2 & & 12 & 24 \\
$\begin{array}{c}\text { Class-III } \\
\text { Grand total }\end{array}$ & 12 & 48 & 96 \\
\hline
\end{tabular}

Mean and standard deviation (descriptive statistics) of different variables Mandibular IMW, Maxillary IMW) compared in this study are given in Table. 2

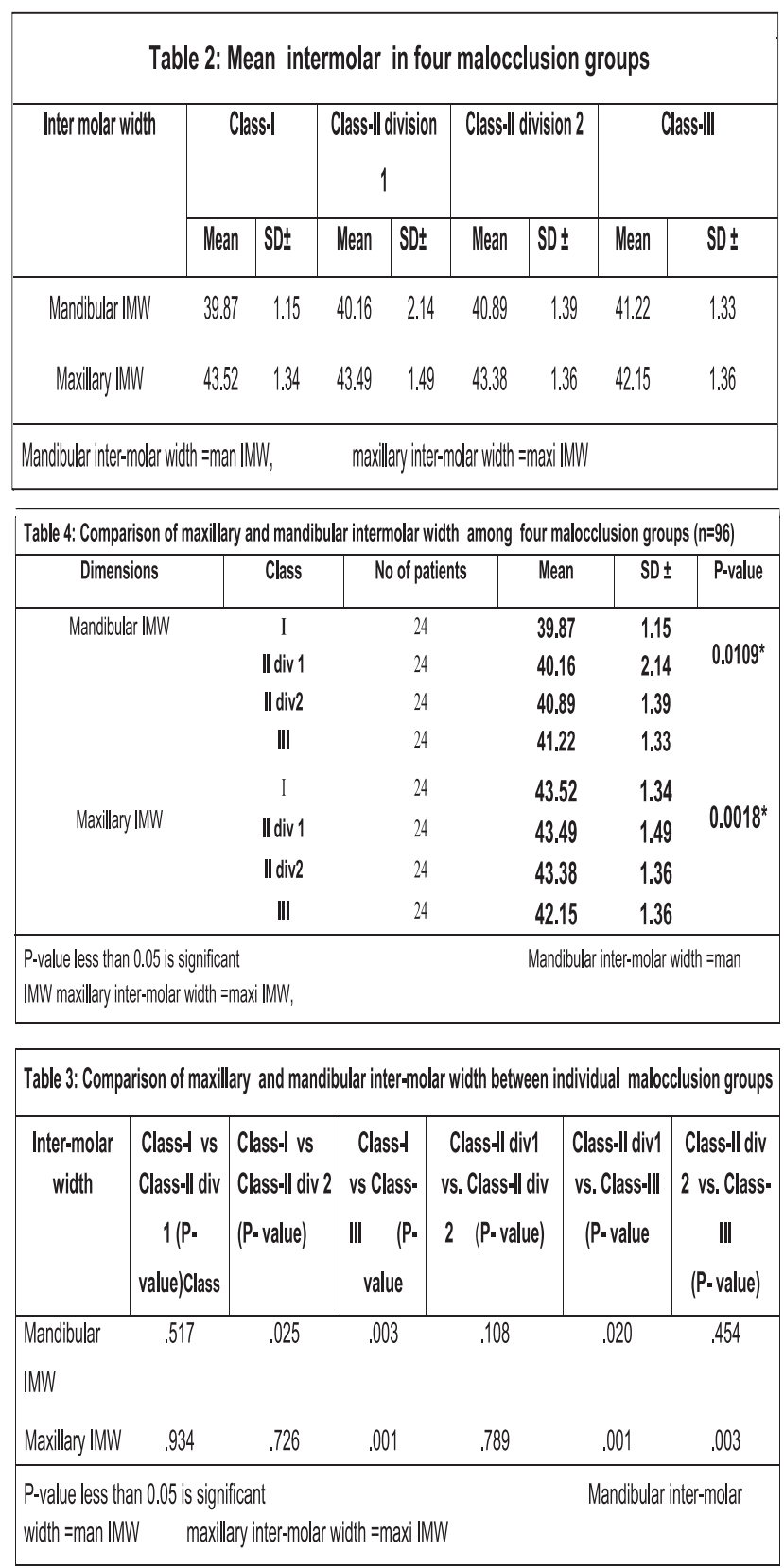




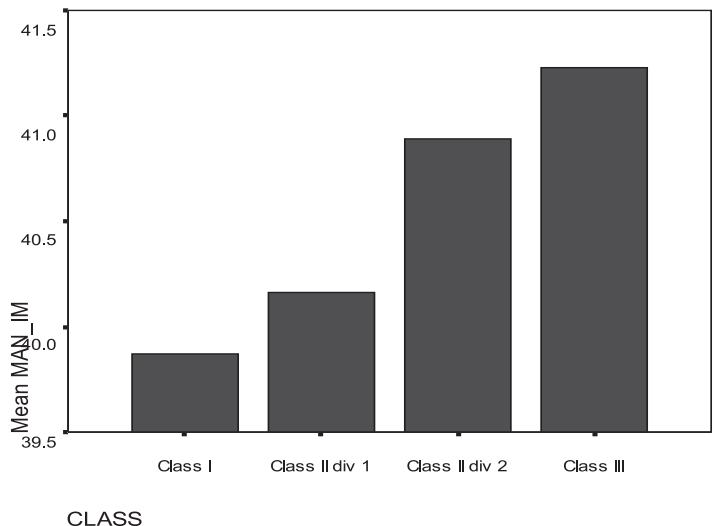

Figure 2: Bar diagram of mean mandibular intermolar width of four groups of malocclusions.

\section{Mandibular Intermolar Width:}

Class I group showed highest mean mandibular intermolar width followed by Class III, followed by Class II div 2, while the lowest value was noted for Class I group. The difference in mandibular intermolar widths among the four groups was found to be significant ( $p$ $=0.0109$ ) as shown in Table 4. No two individual groups showed significant difference except Class-I and Class II div 2, Class I and Class III, Class II div1 and Class III (Table 3), implying that mandibular arches were more constricted in Class I group than in class III malocclusion

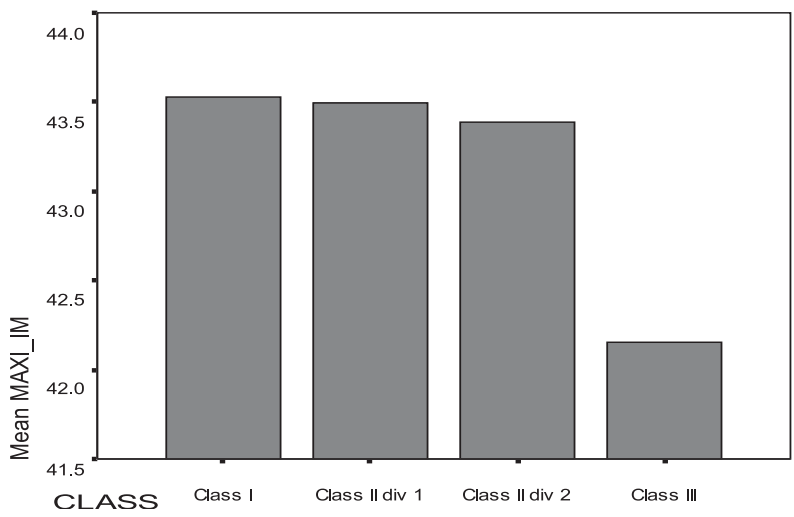

Figure 3: Bar diagram of mean maxillary intermolar width of four groups of malocclusions.

\section{Maxillary Intermolar Width:}

The highest mean intermolar width was noted for Class I followed by Class II div 1, followed by class II div 2 malocclusion group with the least width found for class I malocclusion (Table 2 and Figure 3). However, statistically significant difference $(p=0.0018)$ was found when the results is compared among the four malocclusion groups (Table 4). No group showed any significant difference except Class I and Class III, Class II div1 and Class III, Class II div 2 and Class III, when compared individually using LSD test (Table 3).

\section{Discussion :}

Mandibular intermolar width was compared among the different groups of malocclusion and found significant difference ( $p$ value $=0.0109$ ) but this result was different with study done by some other $[5,6]$.In this study we found class III malocclusion has maximum intermolar width and it was a also found in the another study [7]

Maxillary inter-molar width was compared among four groups of malocclusion in this study and we found there was significant difference ( $p$ value $=0.0018$ ) between them. When individual group is compared significant difference was also found between Class I and ClassIII ( $p$ value $=0.001)$, Classll div. 1 and ClassllI ( $p$ value $=0.001$ ), Class II div 2 and ClassIII ( $p$ value $=0.003$ ). It was found that Class I malocclusion has is greater than class II malocclusion. Similar result was found in a study by another author [8]

\section{Conclusion :}

In different types of malocclusion of permanent dentition, intermolar width is measured on maxillary and mandibular dental casts. From the result, it may be concluded and suggested that

1.Class III malocclusion has maximum mandibular intermolar width. It suggested that growth in transverse plane in class III is more than normo-occlusion. It was also found that class I malocclusion show minimum mandibular intermolar width.

2. Maxillary intermolar distance is widest in class I malocclusion . It is narrowest and frequently associated with posterior cross bite in class III malocclusion.

\section{References :}

1. Lee RT. Arch width and form: a review. Am J Orthod. 1999; 115:305-13

2. Biggerstaff $\mathrm{RH}$. Three variations in dental arch form estimated by a quadratic equation. J Dent Res 1972; 51: 15091515.

3. Rosool G, Kundi I. Comparison of dental arch dimensions among various malocclusion classes. J. Med. Sci.(Peshawar print) july 2009, vol.17,No.2: 71-77

4. Rahman MM and Hossain MZ . estimation of the arch width in first molar teeth in the normal occlusion in Bangladeshi population. Bangladesh journal of Orthdontics and dentofacial orthopedic .Vol.1 No. 2. 2011

5. Bishara SE, Bayati P, Jakobsen JR. Longitudinal comparisons of dental arch changes in normal and untreated Class II, Division 1 subjects and their clinical implications. Am J Orthod Dentofacial Orthop 1996; 110: 483-9.

6. Hashim HA, Al Ghamdi HS. Arch dimensions in Class I, II and III malocclusion: A pilot study. Pak J Orthodont Ped and Comm Dentistry 2002; 1: 21-6.

7. Al-Khateeb SN, Abu-Alhaija ESJ. Tooth size discrepancies and arch parameters among different malocclusions in a Jordanian sample. Angle Orthod 2006; 76: 459-65.

8. Quraishi BA. Comparison of arch widths in adults with normal occlusion and adults with Class II Division 1 and Class III malocclusion [Dissertation]. Karachi, Pakistan: College of Physicians and Surgeons Pakistan; 2004. 